\title{
HEMATOLOGIA DE FRANGOS ALIMENTADOS COM DIETAS CONTENDO AFLATOXINAS E ADSORVENTE DE TOXINAS
}

\author{
HEMATOLOGY OF BROILERS FED DIETS CONTAINING \\ AFLATOXINS AND MYCOTOXIN ADSORBENT
}

\begin{abstract}
Roll, V.F.B. ${ }^{1 \star}$, Lopes, L.L. ${ }^{1}$, Rossi, P. ${ }^{1}$, Anciuti, M.A. ${ }^{2}$, Rutz, F. ${ }^{1}$, Xavier, E.G. ${ }^{1}$ e Silva, S.S. ${ }^{3}$
${ }^{1}$ Departamento de Zootecnia. Faculdade de Agronomia Eliseu Maciel. FAEM-UFPEL. Campus Universitário s/n. Cx. Postal 354. CEP 96010-900. Pelotas. RS, Brasil. *roll98@ufpel.edu.br ${ }^{2}$ Conjunto Agrotécnico Visconde da Graça. CAVG-UFPEL. Av. Idelfonso Simões Lopes, 2791. Cx. Postal 460. CEP 96060-290. Pelotas. RS, Brasil.

${ }^{3}$ Faculdade de Veterinária da UFPEL. Departamento de Veterinária Preventiva. Campus Universitário s/n. Cx. Postal 354. CEP 96010-900. Pelotas. RS, Brasil.
\end{abstract}

\section{PalaVRas chaVe adicionais}

Heterófilos. Linfócitos. Bem-estar. Estresse.

\section{RESUMO}

Avaliou-se o efeito de adsorventes de micotoxinas a base de glucomananos esterificados Mycosorb ${ }^{\circledR}$ sobre a taxa de hematócrito, relação heterófilos/linfócitos circulantes e peso vivo em frangos de corte Ross fêmeas alimentados com dietas contaminadas ou não com aflatoxina. Aos 37,44 e 51 dias de idade foram coletadas amostras de sangue para realizar o hematócrito e a contagem de leucócitos total e diferencial. Na contagem leucocitária diferencial são apresentados apenas os linfócitos e heterófilos em função do objetivo do trabalho, calculando-se a proporção de cada tipo em cem células contadas. A relação heterófilos/ linfócitos foi calculada dividindo-se a taxa de heterófilos pela taxa de linfócitos. Os tratamentos com sete repetições de 28 aves cada, totalizando 784 aves, foram assim constituídos: $T 1=$ Dieta com milho não contaminado (controle), T2= Dieta com milho contaminado (aflatoxina $1 \mathrm{ppm}$ ) sem adsorventes, $\mathrm{T} 3=$ Dieta com milho contaminado (aflatoxina $1 \mathrm{ppm}$ ) $+1,0 \mathrm{~kg} / \mathrm{t}$ adsorvente Mycosorb $\AA, T 4=$ Dieta com milho não contaminado $+1,0 \mathrm{~kg} / \mathrm{t}$ adsorvente Mycosorb ${ }^{\circledR}$. Os dados foram submetidos à análise de variância e as médias de cada tratamento comparadas através do teste de Duncan. Aves alimentadas com milho contaminado e sem adsorvente de micotoxinas (T2) apresentaram, numericamente, em todas as idades, a maior taxa de hematócrito. No entanto, diferenças

Recibido: 16-1-08. Aceptado: 14-5-08.
AdDitionAL KEYWORDS

Heterophils. Lymphocytes. Welfare. Stress.

significativas $(p<0,05)$ foram encontradas somente entre o milho contaminado sem adsorvente (T2) comparado ao milho não contaminado com aflatoxina com adsorvente de micotoxinas (T4) aos 37 e 44 dias de idade. A maior diferença na relação heterófilo/linfócito foi observada entre as aves que receberam dieta com milho não contaminado sem adsorvente comparada com a dieta com milho não contaminado suplementada com $1 \mathrm{~kg} / \mathrm{t}$ de adsorvente (32 vs. $16 \%, \mathrm{p}<0,05$ ). As aves alimentadas com dietas contendo aflatoxina sem adsorvente apresentaram menor ganho de peso $(p<0,05)$ aos 51 dias de idade, quando comparadas com aves recebendo dietas contaminadas suplementadas com adsorventes (2078,0 vs. $2501,2 \mathrm{~kg}$, respectivamente). Conclui-se que a suplementação de adsorvente a base de glucomanano esterificado (Mycosorb® $1 \mathrm{~kg} / \mathrm{t}$ ), em dietas com ou sem milho contaminado com aflatoxina, influencia positivamente o hematócrito e o peso vivo e melhora o bem-estar animal avaliado através da relação heterófilos/linfócitos circulantes em frangos de corte fêmeas.

\section{SUMMARY}

A research was conducted to evaluate the effect of mycotoxins' adsorbent Mycosorb ${ }^{\circledR}$ on the hematological parameters of broilers (Ross) fed 
diets contaminated or not with aflatoxins. The welfare of broilers was determined by measuring heterophil/lymphocyte ratio. Blood samples were collected at 37, 44 and 51 days of age for the counting of total and differential leukocytes. Leukocytes counting were determined for lymphocytes and heterophils. The counting was based on the proportion of each cell type present in 100 counted cells. Heterophil/lymphocyte ratio was obtained dividing the rate of heterophils by the rate of lymphocytes. A total of 784 birds were used. Four treatments (seven replications of 28 birds each) were studied: $\mathrm{T} 1=$ non contaminated corn (control); T2 = contaminated corn $(1 \mathrm{ppm}$ aflatoxin) without adsorbent; T3= contaminated corn (1 ppm aflatoxin) + 1 kg Mycosorb ${ }^{\circledR} / \mathrm{t}$; and T4= non contaminated corn $+1 \mathrm{~kg}$ Mycosorb ${ }^{\circledR} / \mathrm{t}$. Data were analyzed through ANOVA and Duncan test was used for comparing the treatment means. Birds fed diets containing contaminated corn without mycotoxin adsorbent (T2) showed the highest numeric hematocrit index for all ages. However, significant differences $(p<0.05)$ were found only among contaminated corn without adsorbent (T2) compared to uncontaminated corn containing mycotoxin adsorbent (T4) at 37 and 44 days of age. The highest heterophil/lymphocyte difference was observed among birds fed diets containing non contaminated corn without adsorbent in comparison to the ones fed diets containing non contaminated corn supplemented with $1 \mathrm{~kg}$ adsorbent/kg (32 vs. 16\%, p<0.05). Birds fed diets containing aflatoxin without adsorbent showed lower weight gain $(p<0.05)$ at 51 days when compared to the ones fed contaminated diets supplemented with adsorbent (2078.0 vs. $2501.2 \mathrm{~kg}$, respectively). In conclusion, dietary supplementation of adsorbent based on sterified glucomannan (Mycosorb ${ }^{\circledR} / 1 \mathrm{~kg} / \mathrm{t}$ ) in diets with or without contaminated corn positively affects hematocrit and live weight and improves animal welfare of female broilers, as evaluated through heterophil/lymphocyte ratio.

\section{INTRODUÇÃO}

A presença de micotoxinas nas dietas de frangos de corte pode causar sérios problemas à saúde e ao bem-estar dos animais. As micotoxicoses afetam negativamente a taxa de crescimento, a conversão alimentar e a eficiência reprodutiva de um plantel, repercutindo sobre a relação custo-benefício das indústrias avícolas (Santin et al., 2001). Por definição micotoxinas são metabólitos tóxicos de natureza química heterogênea produzidos por fungos e com efeitos farmacológicos distintos, resultando na diminuição do desempenho de frangos de corte (Huff et al., 1988) sendo a aflatoxina B1 a mais frequentemente encontrada (Leeson et al., 1995).

Estudos têm sido dirigidos para o uso de adsorventes, naturais ou sintéticos, na tentativa de minimizar os efeitos da ingestão de alimentos contaminados com micotoxinas (Swamy et al., 2002; Aravind et al., 2003). Segundo Olver (1997), os adsorventes possuem a habilidade de se aderir à toxina e impedir sua absorção pelo trato gastrintestinal tornando-a inerte e não tóxica para os animais.

Animais sob estresse apresentam modificações metabólicas expressas por alterações bioquímicas e hematológicas (Laganá et al., 2007). O hematócrito corresponde à percentagem de glóbulos vermelhos em função do volume total de sangue e é um importante fator que determina o grau de anemia e padrões de transporte de gases (Maxwell et al., 1992). Por outro lado, a principal função dos heterófilos é de fagocitose (Morgulis, 2002), que se realiza como resposta a um estímulo quimiotático. Os linfócitos são os responsáveis pela imunidade específica e iniciam as reações de adaptação do organismo.

O glucomanano derivado da parede celular de levedura avaliado neste estudo tem mostrado respostas positivas sobre o desempenho de frangos de corte reduzindo o impacto da contaminação com micotoxinas na dieta (Smith et al., 2000; Swany et al., 2002; Aravind et al., 2003, Swamy, 2005).

O aumento na relação de heterófilos/ linfócitos circulantes tem sido relacionada com estresse crônico em frangos (Gross e Siegel, 1983; Jones et al., 1988) podendo ser esta variável mais confiável para avaliar o bem-estar de aves que a concentração de corticosterona no plasma (Maxwel, 1993).

Archivos de zootecnia vol. 59, núm. 225, p. 94. 
Desta forma, o objetivo deste trabalho foi de verificar o efeito de adsorvente de toxina Mycosorb ${ }^{\circledR}$ sobre o bem-estar das aves avaliado através da relação heterófilos/ linfócitos circulantes e hematócrito e estimar o ganho de peso em frangos de corte alimentados com dietas contendo ou não milho contaminado com aflatoxina.

\section{MATERIAL EMÉTODOS}

Foram utilizados 784 frangos de corte fêmeas Ross alojadas de um a 51 dias de idade no período de dezembro de 2006 a janeiro de 2007. No decorrer do experimento, foram identificados com anilhas, ao acaso, um frango por repetição (total sete aves por tratamento) para a coleta de sangue que ocorreu aos 37, 44 e 51 dias de idade. Para a realização das análises hematológicas o sangue coletado foi identificado e colocado em tubos ependorf com anticoagulante (ácido etilenodiaminotetraacético), na proporção de $0,8 \mu \mathrm{l}$ para $0,5 \mathrm{ml}$ de sangue.

A determinação do hematócrito foi realizada através do método do microhematócrito, utilizando-se tubo capilar centrifugado a $1200 \mathrm{rpm}$ por 5 minutos em centrifugas sendo os resultados estimados em porcentagem através de tabelas específicas de microhematócrito.

Na contagem de leucócitos, utilizou-se uma amostra de sangue e solução de Natt e Herrick'sb, em uma diluição de 1:200, realizando-se a contagem em câmara de Neubauer, sendo contadas as células nos quadrados pequenos centrais e o resultado multiplicado por 120. Para a contagem diferencial leucocitária, preparou-se um esfregaço sanguíneo emlâminas de vidro, fixado comálcool metílico (Metanol) durante 5 minutos e posteriormente corado com hematoxilina-eosina (Panótipo rápido). As lâminas foram lavadas com água destilada, secadas ao ar livre e os esfregaços foram observados ao microscópio ótico com objetiva de imersão. A contagem leucocitária foi classificatória em granulares (heterófilos, eosinófilos e basófilos) e não granulares (linfócitos, e monócitos). No entanto, para os objetivos deste trabalho são apresentados apenas os valores de heterófilos e linfócitos. A relação heterófilos /linfócitos foi calculada de acordo com (Gross e Siegel, 1983).

Os tratamentos ficaram assim constituídos: T1= Dieta com milho não contaminado (controle), T2= Dieta com milho contaminado (aflatoxina $1 \mathrm{ppm}$ ) sem adsorventes, T3= Dieta com milho contaminado (aflatoxina $1 \mathrm{ppm}$ ) $+1,0 \mathrm{~kg} /$ t adsorvente Mycosorb $®$, T4= Dieta com milho não contaminado $+1,0 \mathrm{~kg} /$ t adsorvente Mycosorb ${ }^{\circledR}$. As dietas experimentais foram formuladas dentro do esquema de três fases: Pré-inicial 1-12 dias, inicial 12-28 dias, crescimento e terminação 29-35 dias. A dieta basal era constituída de milho farelo de soja. Fontes vitamínicas e minerais formuladas de maneira a atender as necessidades nutricionais em cada fase de acordo com a recomendação do manual da linhagem (tabela I).

O delineamento experimental foi inteiramente casualizado, constituído de quatro tratamentos com sete repetições de 28 aves cada. Foram utilizados 28 boxes, com uma densidade inicial de 28 aves em cada boxe (15 aves $/ \mathrm{m}^{2}$ ).

O modelo estatístico foi o seguinte:

$$
Y_{i k}=\mu+A_{i+} \beta_{j}+(A \beta)_{i j}+E_{i j k}
$$

Emque:

$\mathrm{Y}_{\mathrm{ik}}=$ variável resposta na repetição $\mathrm{k}$, nível i de A; $\mu=$ média geral;

$A_{i}=$ efeito do tratamento ao nível ( $\left.i=1,2,3,4\right)$;

$\beta=$ efeito da idade ao nível $(i=1,2,3)$;

$(A \beta)_{i j}=$ efeito da interação $A \beta$ ao nivel $i, j$; $\mathrm{E}_{\mathrm{ijk}}=$ Erro aleatório.

Os dados foram submetidos à análise de variância e as médias de cada tratamento comparadas através do teste de Duncan.

\section{RESULTADOSEDISCUSSÃO}

$\mathrm{Na}$ tabela II observa-se que as aves alimentadas com milho contaminado e sem 
ROLL, LOPES, ROSSI, ANCIUTI, RUTZ, XAVIER E SILVA

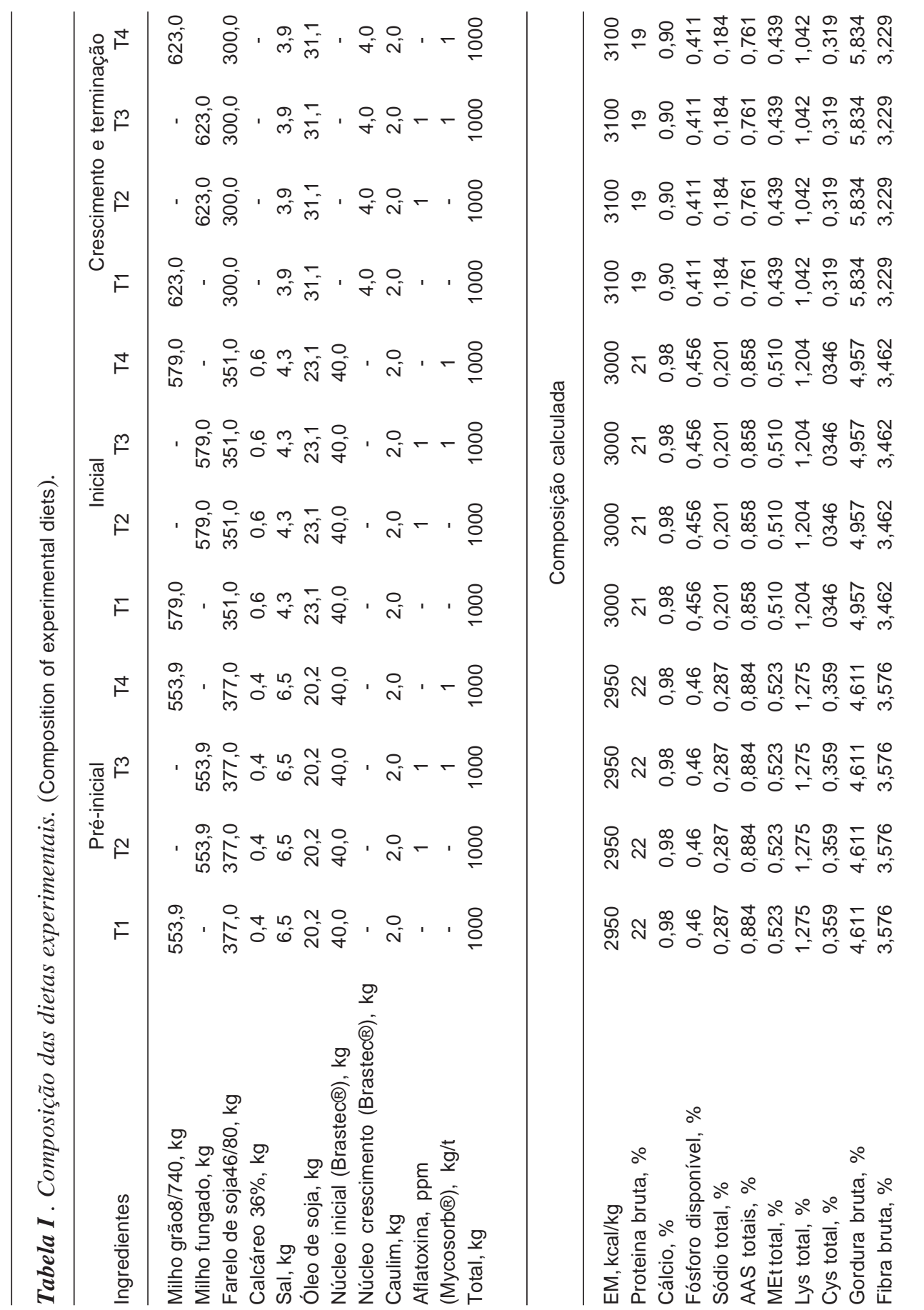

Archivos de zootecnia vol. 59, núm. 225, p. 96. 
adsorvente de micotoxinas (T2) apresentaram, numericamente, em todas as idades, a maior taxa de hematócrito. No entanto, diferenças significativas $(\mathrm{p}<0,05)$ foram encontradas entre as dietas contendo milho contaminado sem adsorvente (T2) comparado a dieta com milho não contaminado com aflatoxina e com adsorvente de micotoxinas (T4) aos 37 e 44 dias de idade. Na avaliação total, onde são englobadas todas as idades, se observa que a inclusão de $1 \mathrm{~kg}$ de adsorvente por tonelada de ração contaminada ocasionou a redução de até 5\% no hematócrito comparado a ração contaminada sem adsorventes (32,3 vs. 27,5\%, $\mathrm{p}<0,05)$, possivelmente indicando um processo de desidratação em aves recebendo dietas contendo milho contaminado sem a adição de Mycosorb.

Maxwell et al. (1992) encontraram taxas de hematócrito 27,1 para aves normais e $37,2 \%$ para aves ascíticas. Estes resultados indicam que as aves tratadas com $1 \mathrm{~kg} / \mathrm{t}$ de adsorvente encontram-se fisiologicamente mais próximas aos parâmetros normais daquelas aves. Os frangos por desenvolverem-se muito rápido apresentam restrições do tipo anatômicas e fisiológicas no sistema cardio-respiratório podendo ocorrer baixa oxigenação durante o período de crescimento (Hernandez, 2000).

Os resultados apresentados na tabela II são semelhantes aos encontrados por
Silversides et al. (1997) que avaliaram o valor de hematócrito em nove linhagens comerciais de frangos de corte. Os autores constataram separando as aves em dois grupos, aos 21 e aos 42 dias de idade, valores de hematócrito variando entre 28,8 a $32,9 \%$ e 27,1 a 33,8\% na primeira e segunda idade, respectivamente, em cada grupo. Lubritz e McPherson (1994) utilizando-se do frio como fator estressante também encontraram diferenças entre três genótipos para o hematócrito, sendo as aves estressadas as que apresentaram maior valor.

O estresse calórico provoca alterações quantitativas e morfológicas nas células sangüíneas aumentando o número de hemácias e o hematócrito (Borges et al., 2003), possivelmente por um processo de desidratação. Tendo em vista que o experimento foi realizado no verão com temperaturas internas médias altas e que houve a redução no hematócrito dentro de níveis normais com a utilização de adsorventes supõe-se que a utilização deste aditivo na dosagem de $1,0 \mathrm{~kg} / \mathrm{t}$ proporciona melhor resistência ao calor e bem-estar as aves.

O aumento na demanda de oxigênio provocado por diversos fatores, incluindo alta taxa de crescimento, variações climáticas, reações vacinais, alta densidade nas instalações, concentração de amônia, patologias, entre outras, ativa mecanismos compensatórios para manter a homeostase

Tabela II. Efeito dos adsorventes de toxina sobre o hematócrito em frangos de corte alimentados com dietas com ou sem milho contaminado com aflatoxina (médias terro padrão). (Effects of mycotoxin adsorbent on hematocrit of broilers fed diets contaminated or not with aflatoxins (means \pm error)).

\begin{tabular}{lcccc}
\hline & \multicolumn{4}{c}{ Idade } \\
Tratamento & 37 & 44 & 51 & Total (Trat) \\
\hline Milho não contaminado sem adsorvente & $31,3 \pm 1,0^{\mathrm{AB}}$ & $28,3 \pm 1,8^{\mathrm{AB}}$ & $31,8 \pm 1,0^{\mathrm{A}}$ & $30,5 \pm 0,79^{\mathrm{AB}}$ \\
Milho contaminado com aflatoxina sem adsorvente & $32,4 \pm 1,3^{\mathrm{A}}$ & $30,9 \pm 0,5^{\mathrm{A}}$ & $33,7 \pm 1,5^{\mathrm{A}}$ & $32,3 \pm 0,67^{\mathrm{A}}$ \\
Milho contaminado com aflatoxina + adsorvente* $^{*} 29,7 \pm 0,90^{\mathrm{AB}}$ & $24,6 \pm 1,1^{\mathrm{C}}$ & $28,5 \pm 4,1^{\mathrm{A}}$ & $27,50 \pm 0,8^{\mathrm{C}}$ \\
Milho não contaminado + adsorvente* & $28,6 \pm 0,7^{\mathrm{B}}$ & $26,4 \pm 0,6^{\mathrm{BC}}$ & $30,0 \pm 0,81^{\mathrm{A}}$ & $28,1 \pm 0,51^{\mathrm{B}}$ \\
\hline
\end{tabular}

*1,0 kg/t. Letras distintas maiúsculas na mesma coluna diferem entre si pelo teste de Duncan $p<0,05$. 
aumentando o fluxo sanguíneo, volume sistólico e retorno venoso levando nos casos mais graves ao aumento da viscosidade do sangue e do hematócrito (Rosário et al., 2004). Pelo menos cinco destes fatores, entre eles, reações vacinais, alta densidade, estresse calórico, concentração de amônia e micotoxinas estavam presentes neste estudo indicando, outra vez, que a presença de adsorventes nas dietas pode auxiliar a manutenção da homeotase das aves frente aos agentes estressantes mais comuns nas granjas comerciais.

Relativamente poucos estudos avaliaram os efeitos de adsorventes de micotoxinas sobre a taxa de hematócrito. Watts etal.(2003) testando a eficiência de aluminosilicato de cálcio e sódio hidratado em frangos alimentados com dietas naturalmente contaminadas com baixos níveis de múltiplas toxinas não observaram nenhum efeito das toxinas sobre a taxa de hematócrito (35,5 vs. 34,7\%). Naquele trabalho os autores verificaram que o aluminosilicato não influenciou a taxa de hematócrito ao mesmo tempo em que foi ineficiente para diminuir o efeito nocivo das toxinas sobre o desempenho. Aravind et al. (2003) determinaram que a utilização de adsorventes aumentou o hematócrito em 2,7\% aos 21 dias, mas não aos 35 dias de idade. Raju e Devegowda (2000) observaram que a utilização de glucomanano esterificado melhorou o peso corporal em 2,26\% e aumentou a taxa de hemoglobina em 3,1\% em relação ao controle. De acordo com a revisão bibliográfica, em geral observa-se que o hematócrito aumenta em situações de estresse, embora possa ocorrer um decréscimo acentuado em casos de intoxicação por níveis muito elevados de toxinas, doenças agudas ou crônicas, septicemias e doenças hemorrágicas.

Os efeitos do uso de adsorventes sobre relação heterófilo/linfócitos em frangos alimentados com dietas contendo ou não milho contaminado com aflatoxina encontram-se na tabela III.

As aves alimentadas com milho não contaminado e com adsorvente de toxinas (T4) apresentaram significativamente as menores relações heterófilos/linfócitos comparadas àquelas aves que receberam dietas contendo ou não milho fungado, mas sem adsorvente (T1-T2). Foram observados valores maiores que 0,3 para a relação heterófilos/linfócitos somente no tratamento milho não contaminado sem adsorvente (T1). Níveis mais altos na relação heterófilos/ linfócitos circulantes são considerados indicadores de estresse nas aves (Gross e Siegel, 1983; Jones et al., 1988; Malley e Snowden, 1999). Neste caso todas as aves

Tabela III. Valores relativos e absolutos de heterófilos, linfócitos e a relação heterófilos/ linfócitos obtidos de sete aves por tratamento em três períodos de coleta (37, 44, 51 dias de idade). (Percentage and absolute values for heterophils, lymphocytes, and heterophil/lymphocyte ratio obtained from seven birds/treatment in three blood collection periods (37, 44, 51 days of age)).

\begin{tabular}{lcccc}
\hline & \multicolumn{3}{c}{ Tratamentos } \\
Milho & \multicolumn{2}{c}{$\begin{array}{c}\text { Sem adsorvente } \\
\text { não contaminado }\end{array}$} & $\begin{array}{c}\text { Com adsorvente } 1,0 \mathrm{~kg} / \mathrm{t} \\
\text { comatoxina }\end{array}$ & $\begin{array}{c}\text { com aflatoxina } \\
\text { não contaminado }\end{array}$ \\
\hline Heterófilo/linfócito & $0,32 \pm 0,03^{\mathrm{A}}$ & $0,28 \pm 0,03^{\mathrm{AB}}$ & $0,22 \pm 0,02 \mathrm{~B}^{\mathrm{C}}$ & $0,16 \pm 0,01^{\mathrm{C}}$ \\
Heterófilos, \% & $23,05 \pm 1,67^{\mathrm{A}}$ & $21,3 \pm 1,6^{\mathrm{A}}$ & $17,4 \pm 1,5^{\mathrm{B}}$ & $13,3 \pm 0,7^{\mathrm{C}}$ \\
Heterófilos/ $\mu \mathrm{l}$ & $999,47 \pm 110,1^{\mathrm{AB}}$ & $1226,4 \pm 123,6^{\mathrm{A}}$ & $852,1 \pm 107,6^{\mathrm{B}}$ & $787,6 \pm 49,8^{\mathrm{B}}$ \\
Linfócitos, \% & $75,4 \pm 1,7^{\mathrm{C}}$ & $78,1 \pm 1,7 \mathrm{~B}^{\mathrm{C}}$ & $79,9 \pm 1,3^{\mathrm{B}}$ & $85,4 \pm 0,7^{\mathrm{A}}$ \\
Linfócitos/ $\mu \mathrm{l}$ & $3141,8 \pm 213,4^{\mathrm{C}}$ & $4410,2 \pm 232,7^{\mathrm{AB}}$ & $3910,3 \pm 349,5^{\mathrm{BC}}$ & $5070,3 \pm 269,2^{\mathrm{A}}$ \\
\hline
\end{tabular}

Letras distintas maiúsculas na mesma linha diferem entre si pelo teste de Duncan $(p<0,05)$.

Archivos de zootecnia vol. 59, núm. 225, p. 98. 
que receberam adsorventes de micotoxinas na dieta apresentaram-se numericamente superiores em termos de bem-estar. A maior diferença na relação heterófilo/linfócito $(p<0,05)$ ocorreu entre as dietas de milho não contaminado sem adsorvente (T1) comparada com a dieta milho não contaminado com adsorvente (T2), 32 vs. 16\%, respectivamente. A partir destes resultados é possível inferir que a utilização de adsorventes de micotoxinas a base de glucamanano esterificado Mycosorb 1,0 kg/ton promove o bem-estar das aves inclusive naquelas dietas que supostamente estariam isentas de micotoxinas.

A administração de glucocorticoides causa linfopenia e aumento no heterófilo circulante (Harmon, 1998). Os corticoides promovem a liberação de heterófilos do sistema hematopoiético para a circulação (Jain, 1993). O número de leucócitos muda mais lentamente (30 min às $20 \mathrm{~h}$ ) em resposta ao estresse que os níveis de corticosterona (Maxwell, 1993). Por esta razão a relação heterófilos/linfócitos tem sido indicada como um indicador confiável para estresse crônico em aves enquanto que o nível de corticosterona seria melhor para medir estresse agudo (Gross e Siegel, 1983).

Hocking (1993) observou que a restrição alimentar em frangos aumentou os basófilos, heterófilos e a relação heterófilos/ linfócitos enquanto reduziu os linfócitos. De forma semelhante Beuving et al., 1989 encontraram maior relação heterófilo/ linfócito com o aumento progressivo do tempo de restrição alimentar em poedeiras White Leghorn.

Durante o transporte para o local de abate uma serie de fatores estressantes, entre eles, temperatura elevada, vibração, aceleração, impactos, barulho, jejum alimentar e hídrico afetam o bem-estar das aves (Mitchell e Kettlewell, 1998). Essas condições induzem a aumento dos níveis plasmáticos de corticosteróides (Freeman et al., 1984) e do índice heterófilo/linfócito (Maxwell, 1993).
Mitchell e Kettlewell (1998) verificaram que altas temperaturas e umidade relativa do ar durante o transporte, provocam o aumento da temperatura corporal, ocasionando alcalose respiratória aumentando o índice heterófilos/linfócitos. Durante o experimento as aves estiveram submetidas a altas temperaturas e umidade dentro do aviário, por isso seria possível levantar a hipótese de que os adsorventes poderiam atuar de alguma forma diminuindo também a alcalose respiratória.

Observou-se que a porcentagem de heterófilos esteve negativamente correlacionada ao peso corporal (Correlação de Pearson -0,302 $\mathrm{p}=0,001$ ) e a porcentagem de linfócitos, ao contrário, se correlacionou positivamente com o peso corporal (Pearson $0,316, p=0,001)$. A relação heterófilos/ linfócitos se correlacionou negativamente com o peso corporal (Pearson -0,302 $\mathrm{p}=$ $0,001)$. Estes resultados são coerentes com a afirmação de que quanto menor a relação heterófilos/linfócitos melhor é o bem-estar das aves (levando em consideração que frangos de corte sadios ganham peso mais rapidamente). A redução do peso vivo é um dos primeiros sintomas de problemas de bem-estar em aves (Roll, 2005). Desta forma seria possível estimar indiretamente o potencial produtivo do lote através da contagem diferencial de leucócitos, principalmente através da relação heterófilo/ linfócitos. Um aumento na relação de heterófilos/linfócitos circulante tem sido indicado como uma técnica confiável para avaliar estresse crônico em frangos de corte (Gross e Siegel, 1983; Jones et al., 1988).

Os resultados apresentados na tabela IV demonstram que, numericamente, os melhores resultados de peso vivo aos 51 dias de idade foram obtidos com a utilização de adsorventes na dose de $1 \mathrm{~kg} / \mathrm{t}$ de ração, tanto em dietas contaminadas ou não com aflatoxina. Porém, diferenças estatísticas $(p<0,05)$ foram encontradas somente entre a dieta não contaminada com aflatoxina + adsorvente (T4) e a dieta com milho con- 
Tabela IV. Efeito dos adsorventes de toxina sobre o peso vivo em frangos de corte alimentados com dietas contendo milho fungado ou não (médias \pm erro padrão). (Effects of mycotoxin adsorbent on live weight of broilers fed diets contaminated or not with aflatoxins (means \pm error)).

\begin{tabular}{lccc}
\hline & \multicolumn{3}{c}{ Idade } \\
Tratamento & 37 & 44 & 51 \\
\hline milho não contaminado & $1561,1 \pm 75,1^{\mathrm{AB}}$ & $1904,6 \pm 117,1^{\mathrm{BC}}$ & $2337,6 \pm 131,8^{\mathrm{ABC}}$ \\
milho contaminado com aflatoxina sem adsorvente $^{2} 1378,3 \pm 59,2^{\mathrm{B}}$ & $1773,7 \pm 65,5^{\mathrm{C}}$ & $2078 \pm 127,3^{\mathrm{C}}$ \\
milho contaminado com aflatoxina+adsorvente $^{*}$ & $1566 \pm 69,2^{\mathrm{AB}}$ & $2010,3 \pm 71,8^{\mathrm{AB}}$ & $2501,2 \pm 93,2^{\mathrm{AB}}$ \\
milho não contaminado+adsorvente* & $1715 \pm 68,6^{\mathrm{A}}$ & $2160,4 \pm 78,7^{\mathrm{A}}$ & $2561,6 \pm 122,4^{\mathrm{A}}$
\end{tabular}

*1,0 kg/t. Letras distintas maiúsculas na mesma coluna diferem entre si pelo teste de Duncan.

taminado e sem adsorvente (T2). O menor peso vivo foi encontrado nas aves alimentadas com dietas contaminadas com aflatoxina sem adsorventes. Estes resultados concordam com Swamy (2005) que verificou redução no desempenho de aves alimentadas com dietas contendo micotoxinas. As aflatoxinas afetam negativamente o metabolismo das aves inibição da síntese protéica (Santin, 2000) e diminuindo a atividade de varias enzimas na digestão do amido e lipídios podendo, desta forma, re-

\section{BIBLIOGRAFIA}

Aravind, K.L., Patil, V.S., Devegowda, G., Umakantha, B. and Ganpule, S.P. 2003. Efficacy of esterified glucomannan to counteract mycotoxicosis in naturally contaminated feed on performance and serum biochemical and hematological parameters in broilers. Poultry Sci., 82: 571-576.

Beuving, G., Jones, R.B. and Blokhuis, H.J. 1989. Adrenocortical and heterophil/lymphocyte responses to challenge in hens showing short or long tonic immobility reactions. Brit. Poultry Sci., 30: 175-184.

Borges, S.A., Maiorka, A. e Silva, A.V.F. 2003 Fisiologia do estresse calórico e a utilização de eletrólitos em frangos de corte. Ciência Rural, 33: 975-981.

Devegowda, G. and Murthy, T.N.K. 2005. Mycotoxins: theirs effects in poultry and some practical solutions. In: The mycotoxin blue book, Edited by Duarte E. Diaz. Nottingham University sultar em menor ganho de peso (Devegowda e Murthy, 2005).

\section{CONCLUSÃO}

Conclui-se que a suplementação de $1,0 \mathrm{~kg}$ de adsorvente a base de glucomanano esterificado por tonelada de ração com ou sem milho contaminado influencia positivamente o hematócrito e peso vivo ao mesmo tempo em que melhora o bem-estar animal avaliado através da relação heterófilos/linfócitos circulantes em frangos de corte fêmeas.

Press. Louhborough, UK. pp. 25-56.

Freeman, B.M., Kettlewell, P.J., Manning, A.C.C. and Berry, P.S. 1984. Stress of transportation in broilers. Vet. Rec., 114: 286-287.

Gross, W.B. and Siegel, H.S. 1983. Evaluation of the heterophil/ lymphocyte ratio as a measure of stress in chickens. Avian Dis., 27: 972-979.

Harmon, B.G. 1998. Avian heterophils in inflammation and disease resistance. Poultry Sci., 77: 972-977.

Hernandez, A. 2000. Hipoxic ascites in broiler: a review of several studies done in Colombia. Avian Dis., 31: 658-661.

Hocking, P.M. 1993. Welfare of broiler breeder and layer females subjected to food and water control during rearing: Quantifying the degree of restriction. Brit. Poultry Sci., 34: 53.

Huff, W.E., Kubena, L.F. Harvey, R.B. and Doerr, J.A. 1988. mycotoxin interactions in poultry and swine. J. Anim. Sci., 66: 2351-2355.

Archivos de zootecnia vol. 59, núm. 225, p. 100. 


\section{ADSORVENTE DE MICOTOXINA HEMATOLOGIA E GANHO DE PESO EM FRANGOS}

Jain, N.C. 1993. Essentials of veterinary hematology. Comparative hematology of common domestic animals. Lea and Febiger. Philadelphia, PA. 417 pp.

Jones, B.R., Beuving, G. and Blokhuis, H.J. 1988. Tonic immobility and heterophil/lymphocyte responses of the domestic fowl to corticosterone infusion. Physiol. Behav., 42: 249-253.

Lagana, C., Ribeiro, A.M.L. e Gonzalez, F.H.D. 2007, Níveis dietéticos de proteína e gordura e parâmetros bioquímicos, hematológicos e empenamento em frangos de corte estressados pelo calor. Rev. Bras. Zootecn., 36: 1783-1790.

Leeson, S., Diaz, G. and Summers, J.D. 1995. Aflatoxins. In: S. Leeson, G. Diaz and J.D. Summers (Eds.). Poultry Metabolic Disorders and Mycotoxins. University Books. Ontario. Canada. pp. 248-279.

Lubritz, D.L. and McPherson, B.N. 1994. Effect of genotype and cold stress on incidence of ascites in cockerels. J. Appl. Poultry Res., 3: 171-178.

Malley, P.O. and Snowden, J.M. 1999. Emu products. Increasing production and profitability. A report for the Rural Industries Research and Development Corporation, Publication No 99/ 143. Project $N^{\circ}$ Daw-57A. Bentley Delivery Centre WA 6983. Australia. 216 pp.

Maxwell, M.H. 1993. Avian blood leucocycte responses to stress. Worlds Poultry Sci. J., 49: 34-43.

Maxwell, M.H., Robertson, G.W. and McCorquodale, C.C. 1992. Whole blood and plasma viscosity in normal and ascitic broiler chickens. Brit. Poultry Sci., 33: 871-877.

Mitchell, M.A. and Kettlewell, P.J. 1998. Physiological stress and welfare of broiler chickens in transit: solutions not problems!. Poultry Sci., 77: 1803-1814.

Morgulis, M.S. 2002. Imunologia aplicada. In: Macari, M., Furlan, R.I., Gonzales, E. (Eds.). Fisiologia aviária aplicada a frangos de corte. FUNEP/ UNESP. Jaboticabal. $375 \mathrm{pp}$.

Olver, M.D. 1997. Effect of feeding clinoptilolite (zeolite) on the performance of three strains of laying hens. Brit. Poultry Sci., 38: 220-222.

Raju, M.V. and Devegowda, G. 2000. Influence of esterified-glucomannan on performance and organ morphology, serum biochemistry and haematology in broilers exposed to individual and combined mycotoxicosis (aflatoxin, ochratoxin and T-2 toxin). Brit. Poultry Sci., 41: 640-650.

Roll, V.F.B. 2005. Bienestar animal y productividad en gallinas ponedoras comerciales alojadas en jaulas enriquecidas. Tesis Doctoral. Universidad de Zaragoza. España. pp. 277.

Rosario, M.F., Silva, M.A.N., Coelho, A.A.D. e Savino, V.J.M. 2004. Síndrome ascítica em frangos de corte: uma revisão sobre a fisiologia, avaliação e perspectivas. Ciência Rural, 34: 1987-1986.

Santin, E., Maiorka, A., Zanella, I. and Magon, L. 2001. Mycotoxin of Fusarium ssp. in commercial poultry. Ciência Rural, 31: 185-190.

Santin, E. 2000. Micotoxicoses. In: Berchiere Júnior, A.; Macari, M. Doenças das aves. Campinas: FACTA. pp. 379-388.

Silversides, F.G., Lefrancois, M.R. and Villeneuve, P. 1997. The effect of strain of broiler on physiological parameters associated with the ascites syndrome. Poultry Sci., 76: 663-667.

Smith, T.K., Modirsanei, M. and MacDonald, E.J. 2000. The use of binding agents and aminocids supplements for dietary treatment of Fusarium mytoxicoses. In: Biotecnology in the feed industry. Proceedings of Alltech's $16^{\text {th }}$ Annual Symposium. Nottingham University Press. UK. pp. 383-390.

Swamy, H.V.L.N. 2005. Mycotoxicoses in poultry: an overview from the Asia-pacific region. In: Biotechnology in the feed industry. Proceedings of Alltech's $21^{\text {th }}$ Annual Symposium. Nottingham University Press. UK. pp. 75-89.

Swamy, H.V.L.N., Smith, T.K., Cotter, P.F., Boermans, H.J. and Sefton, A.E. 2002. Effects of feeding blends of grains naturally contaminated with Fusarium mycotoxins on production and metabolism in broilers. Poultry Sci., 81: 966975

Watts, C.M., Chen, Y. C., Ledoux, D. R., Broomhead, J.N., Bermudez, A.J. and Rottinghaus, G.E. 2003. Effects of multiple mycotoxins and a hydrated sodium calcium aluminosilicate. Int. J. Poultry Sci., 2: 372-378.

Archivos de zootecnia vol. 59, núm. 225, p. 101. 